
\title{
Resesarch Sulure \\ Why Residents in Southern China Live Longer Than Those in Northern China?
}

\author{
Mengqi Wang \\ School of Geographic Sciences, Nantong University \\ yi huangyi ( $\nabla$ huangyi@ntu.edu.cn ) \\ Nantong University https://orcid.org/0000-0002-3375-5640
}

\section{Research}

Keywords: Life span of human beings, CVD mortality rate, southern China

Posted Date: September 18th, 2020

DOI: https://doi.org/10.21203/rs.3.rs-76051/v1

License: (c) (i) This work is licensed under a Creative Commons Attribution 4.0 International License. Read Full License 


\section{Introduction}

Life expectancy at birth (defined as the mean number of years remaining at birth until death under specific mortality conditions), longevity ratio (defined as the ratio of the population above 80,90 or 100 years of age), Age standard mortality rate (defined as the mortality rate in each age group was multiplied by the standard age specific number of the population) are currently the main and commonly used lifespan indicators to determine the longevity level ${ }^{[1,2,3,4]}$. Higher life expectancy, longevity ratio and lower age standard mortality rate means higher longevity level. The origins of longevity zones are not clear, however, they have been primarily attributed to social development, economic, medical, geographic and environmental, genetic, and lifestyle factors ${ }^{[5,6]}$.

Of note, Mainland China has 31 provinces. The north-south boundary of China is Qingling Mountain and Huai River, therefore, southern China and northern China each contain 15 provinces. Meanwhile, Tibet is included in neither northern China nor southern China because although Tibet is geographically located in the south, the average elevation is over $4500 \mathrm{~m}$, and its temperature, atmospheric pressure, and oxygen content are far lower than those of other provinces, it is known as the third pole of the earth. The other 30 provinces are divided into northern China and southern China by Qingling Mountain and Huai River. The provinces of northern China and southern China are illustrated in Fig.1.

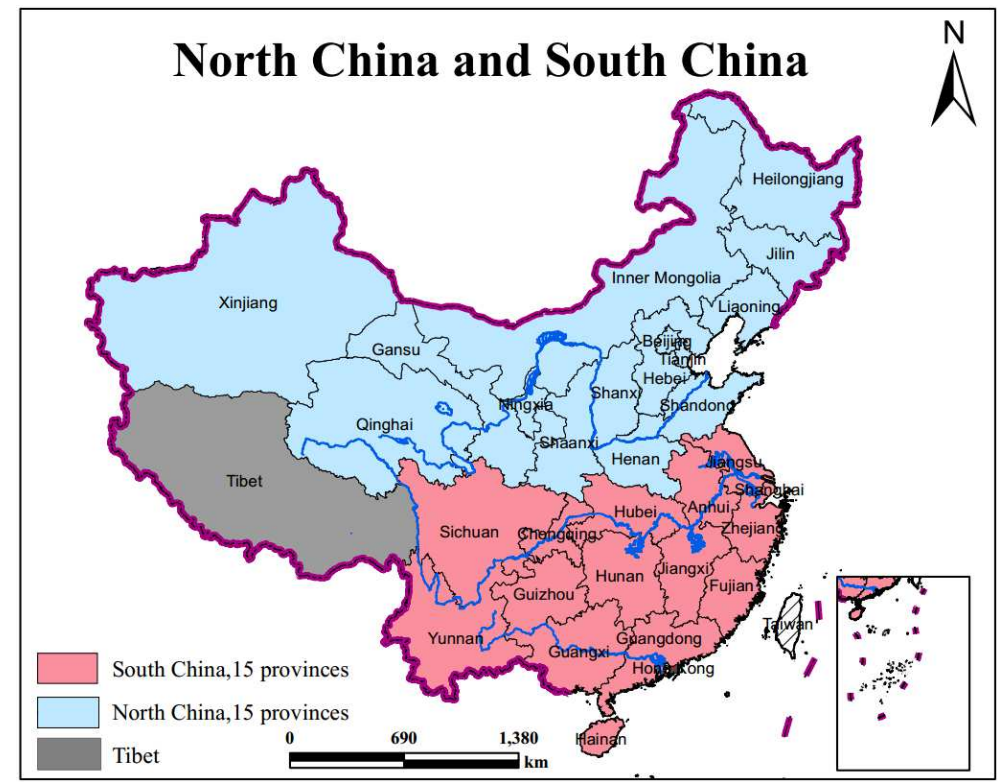

Fig.1 Northern China and Southern China

Since 1982, northern China has consistently showed lower life expectancy and considerably lower longevity ratio $(80+/ 0+, 90+/ 0+$ and $100+/ 0+)$ than southern 
China, while Age standard mortality rate is always higher in northern China than in southern China (Table 1, the data is obtained from the demographic databases of China's third, fourth, fifth, and sixth national population censuses, which were carried out in 1982, 1990, 2000, and 2010 respectively. Life expectancy and centenarian index in 2018 were obtained from aging office of each province.).

31

Table 1. Life span indicators between northern China and southern China

\begin{tabular}{|c|c|c|c|c|c|c|c|c|c|c|}
\hline Indicator & \multicolumn{4}{|c|}{$80+/ 0+(\%)$} & \multicolumn{3}{c|}{$90+/ 0+(1 / 10000)$} & \multicolumn{3}{c|}{ Age standard mortality rate (\%) } \\
\hline Year & 1990 & 2000 & 2010 & 1990 & 2000 & 2010 & 1982 & 1990 & 2000 & 2010 \\
\hline Northern China & 5.683 & 9.056 & 17.72 & 3.01 & 5.85 & 10.16 & 6.617 & 5.695 & 5.678 & 5.732 \\
\hline Southern China & 7.371 & 12.67 & 24.34 & 4.28 & 8.80 & 16.89 & 6.533 & 5.654 & 5.346 & 5.406 \\
\hline Indicator & \multicolumn{4}{|c|}{ Life Expectancy } & \multicolumn{5}{c|}{$100+/ 0+(1 / 100000)$} \\
\hline Year & 1990 & 2000 & 2010 & 2018 & 1982 & 1990 & 2000 & 2010 & 2018 & \\
\hline Northern China & 68.05 & 71.37 & 75.04 & 76.66 & 0.239 & 0.612 & 1.451 & 1.799 & 3.314 & \\
\hline Southern China & 68.54 & 71.58 & 75.21 & 77.35 & 0.387 & 0.722 & 1.720 & 3.755 & 7.285 & \\
\hline
\end{tabular}

Table 1 presents that of all the five longevity indicators, residents in southern China are more longevous than those in northern China from 1982 to 2018. Why residents of southern China far easily live longer compared with those of northern China? Longevity is compactly relative with diseases and their risk factors, and the risk factors of disease can be divided into 2 categories:

(1) Physical geographic and environmental factors, which is including temperature, air quality and air pollution, elevation, etc. Many studies have proved that extreme temperature have a significant impact on mortality ${ }^{[7,8]}$. An excess of deaths is observed during both winter and summer ${ }^{[9,10,11,12]}$. Typically, a U-shaped relationship between temperature and death is observed with mortality risk decreasing from the lowest temperature to an inflection point and then increasing with higher temperature ${ }^{[13]}$. Studies also found that extreme cold temperature can affect deaths occurring not only on the same day, but also on several subsequent days, which is a phenomenon called delayed effects ${ }^{[14]}$. Air pollution and indoor air pollution are leading risk factors of disease burden ${ }^{[15]}$. $\mathrm{PM} 2.5, \mathrm{NO}_{x}, \mathrm{SO}_{2}$, and $\mathrm{O}_{3}$ can induce cardiovascular disease and respiratory disease ${ }^{[16,17,18,19,20,21]}$.

(2) Life style factors, which is including diet sodium intake, diet vegetable and fruit intake, smoke and second hand smoke, alcohol usage, physical activity, lack of sleeping, obesity, mentality, etc. physical activity is an effective way to reduce risk of stroke and heart disease ${ }^{[22]}$. Some study showed that moderate intensity physical activities will decrease risk of CVD by $14 \%$ (HR=0.86, 95\%CI: $0.80-0.93)^{[23]}$. High diet sodium intake is the global primary diet risk factor and the main cause of hypertension and cardiovascular disease, especially in Eastern Asia and China ${ }^{24,25]}$, and hypertension has been the first burden of disease. There is a strong positive 
correlation between obesity and ischemic stroke, risk of ischemic stroke will be increased by $30 \%$ (HR=1.30, 95\%CI: $1.28-1.33)$ along with every $5 \mathrm{~kg} / \mathrm{m}^{2}$ increase of BMI ${ }^{[26]}$. Smoking is associated with 1.3 million cardiovascular events, accounting for

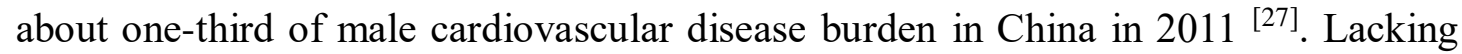
of vegetable and fruit is also an important risk factor of disease, the risk of hypertension decreased with the increase of daily vegetable intake ${ }^{[28]}$.

Although the above factors all have important impacts on disease, health and longevity, the reason of geographic distribution of each factor and the contribution to north-south differential of China is obscure. To address the need for better understanding, we designed the following research process. (1) We collected the mortality rate data of each province, because death is the key cause of regional differentiation in longevity. Life expectancy, standardized mortality, $80+$ rate, $90+$ rate and $100+$ rate are all calculated by or caused by age-specific mortality rate. (2) Disease is the leading cause of death, in China, $97 \%$ of death are caused by disease, among all diseases, CVD (cardiovascular disease and heart diseases), tumors, and respiratory diseases were the three leading causes of death in both rural and urban populations in China, the three diseases accounted for about $80 \%$ of all-cause mortality ${ }^{[29]}$. We collected age standardized mortality rate of CVD, tumors, and respiratory diseases of each provinces and calculated their contribution to longevity differential between northern China and southern China. (3) To figure out the contribution of each risk factor on longevity differential between northern China and southern China, the leading risk factors of the disease in each province were collected, their attributable risk proportion and standardized mortality rate were calculated.

\section{Data, Methodology and Results}

\subsection{Age-standardized rates of four major fatal diseases between northern China and southern China}

To study the reason underlying differences in longevity between northern China and southern China, we selected the mortality rate of major fatal diseases in recent ten years, according to the statistical data of leading mortality causes in China ${ }^{[29]}$, Of all deaths in rural and urban areas, CVD-related deaths accounted for $45.50 \%$ and $43.16 \%$, followed by tumor-related deaths at $22.92 \%$ and $26.06 \%$ and respiratory disease-related deaths at $12.02 \%$ and $11.24 \%$, respectively. Overall, the three diseases accounted for $80.44 \%$ and $80.46 \%$ of all deaths in rural and urban areas, respectively.

CVD can be further divided into cerebrovascular disease and heart diseases. To compare the mortality rates of the four major diseases between northern China and southern China, we collected and mapped the provincial mortality rate data ${ }^{[30,31]}$ 
(Fig.2, major tumors is including lung cancer, liver cancer, stomach cancer, colon and rectum cancer) and proportion of each disease on total age-standardized mortality rates (Fig.3).

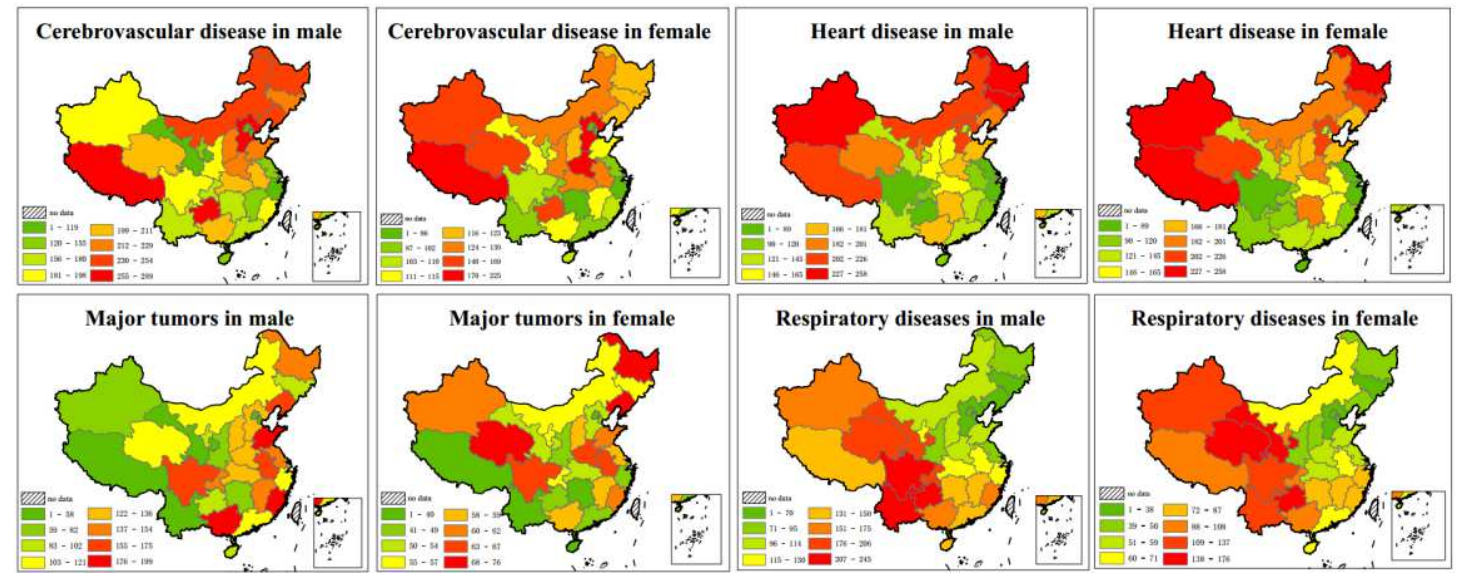

Fig. 2 Distribution of age-standardized mortality rates of four major fatal diseases.

Warmer colors indicate higher mortality rate

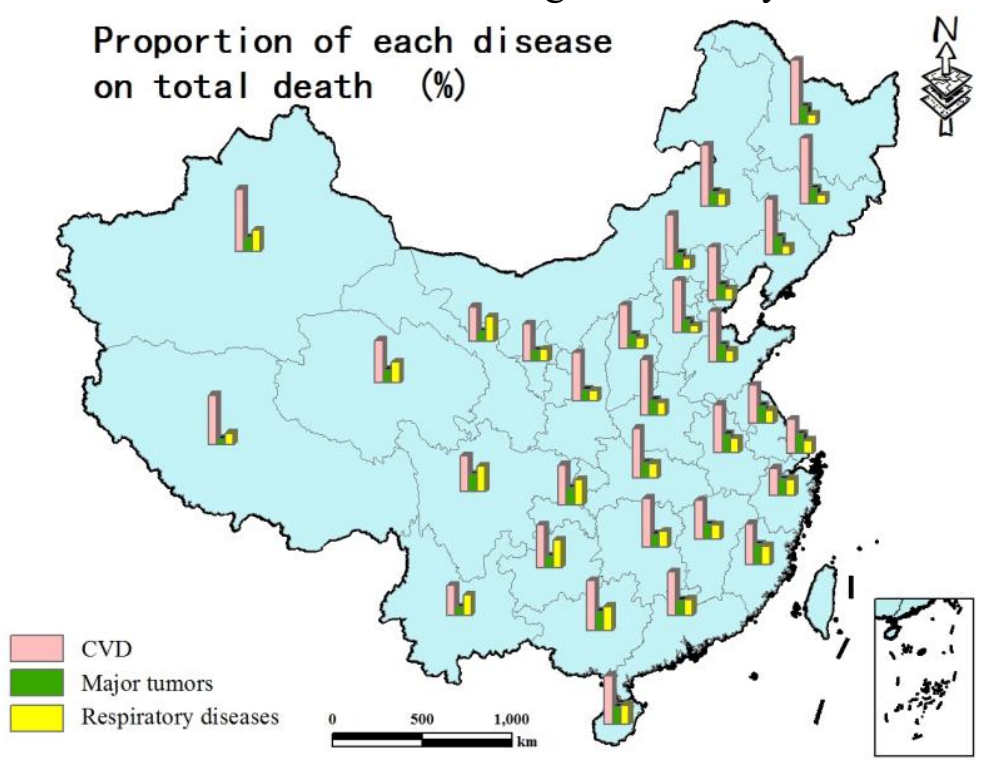

Fig.3 Proportion of each disease on total age-standardized mortality rate

\subsection{Calculation of contribution of each disease to longevity north-south} differential

To evaluate the correlations among the four major diseases and north-south longevity differential, we generated a method to calculate the contribution, as illustrated in Fig.1:

$$
C_{i}=\left(M_{i}^{\text {North }}-M_{i}^{\text {South }}\right) /\left(M_{t}^{\text {North }}-M_{t}^{\text {South }}\right)
$$

Where, $C_{i}$ is contribution value of disease $i$ to the north-south division, $C_{i}>0$ means the disease is positively related with the north-south division, $M$ is Age-standardized mortality rate, $t$ is total mortality rate of the four diseases.

Comparison between northern China and southern China is presented in Table 2. 


\begin{tabular}{|c|c|c|c|c|c|c|c|c|c|}
\hline & \multicolumn{5}{|c|}{ Age-standardized mortality rate, $1 / 100000$} & \multicolumn{4}{|c|}{ Contribution to north-south division } \\
\hline & $\mathrm{CV}$ & HD & $\mathrm{RD}$ & MT & Total & $\mathrm{CV}$ & $\mathrm{HD}$ & $\mathrm{RD}$ & MT \\
\hline Males, north & 199.84 & 196.6 & 99.18 & 130.4 & 626.02 & \multirow{2}{*}{$73 \%$} & \multirow{2}{*}{$167 \%$} & \multirow{2}{*}{$-111 \%$} & \multirow{2}{*}{$-29 \%$} \\
\hline Males, south & 170.88 & 129.9 & 143.4 & 142 & 586.18 & & & & \\
\hline Females, north & 136.15 & 144 & 72.2 & 57.91 & 410.26 & \multirow{2}{*}{$35 \%$} & \multirow{2}{*}{$90 \%$} & \multirow{2}{*}{$-32 \%$} & \multirow{2}{*}{$7 \%$} \\
\hline Females, south & 116.3 & 92.2 & 90.68 & 53.6 & 352.78 & & & & \\
\hline
\end{tabular}

113 CV: Cerebrovascular disease; HD: Heart disease; RD: Respiratory diseases; MT: Major tumors

114 We conducted principal component analyses to determine the associations of the 115 longevity indicators with the major diseases (Table 3). The order in which factors 116 were interpreted was determined based on the magnitude of their eigenvalues. In the 117 result, the eigenvalues of the first factor (F1) are considerably higher than those of F2 118 and F3, therefore, we present the first factor (F1) of principal component analyses in 119 Table 3.

120 Table 3 Principal component analysis of longevity indicators and major diseases

\begin{tabular}{c|cccc|cccc|cc|ccc|ccccc}
\hline & \multicolumn{4}{|c|}{ Life Expectancy } & \multicolumn{4}{c|}{ Age standard mortality rate } & \multicolumn{4}{c}{$80+/ 0+$} & \multicolumn{5}{c}{$100+/ 0+$} \\
\hline & 1990 & 2000 & 2010 & 2018 & 1982 & 1990 & 2000 & 2010 & 1990 & 2000 & 2010 & 1982 & 1990 & 2000 & 2010 & 2018 \\
\hline CV & 0.38 & 0.81 & 0.83 & 0.86 & 0.86 & 0.85 & 0.86 & 0.88 & 0.85 & 0.86 & 0.87 & 0.84 & 0.81 & 0.87 & 0.81 & 0.81 \\
HD & 0.34 & 0.67 & 0.69 & 0.78 & 0.70 & 0.74 & 0.72 & 0.75 & 0.85 & 0.88 & 0.85 & 0.79 & 0.89 & 0.93 & 0.90 & 0.90 \\
RD & -0.07 & -0.24 & -0.20 & -0.13 & -0.18 & -0.22 & -0.25 & -0.15 & -0.09 & -0.12 & -0.07 & -0.33 & -0.21 & -0.12 & -0.16 & -0.18 \\
MT & 0.17 & 0.46 & 0.43 & 0.32 & 0.36 & 0.31 & 0.32 & 0.28 & 0.14 & 0.09 & 0.16 & 0.06 & 0.04 & -0.16 & -0.21 & -0.12 \\
\hline
\end{tabular}

121 CV: Cerebrovascular disease; HD: Heart disease; RD: Respiratory diseases; MT: Major tumors

122 As illustrated in Fig.2, Fig.3, Table 2, Table3, distribution of cerebrovascular 123 disease and heart disease are positively related with north-south differential of 124 age-standardized mortality rates and longevity, because mortality rate of 125 cerebrovascular disease and heart disease is much higher in northern China than in 126 southern China. While distribution of respiratory diseases in negatively related with 127 north-south differential of age-standardized mortality rate and longevity, because 128 mortality rate of respiratory diseases is much higher in southern China than in 129 northern China. There is no obvious north-south difference of distribution of major 130 tumors. Expect those of cerebrovascular disease and heart disease, the sum of all other 131 reasons mortality rate were higher in southern China than in northern China, 132 respectively. Thus, the difference of CVD mortality rate is the fundamental reason for 133 the difference of the longevity level between northern China and southern China.

\subsection{Data collection and calculation of each risk factor on CVD}

In order to study why age standardized mortality rate of cerebrovascular disease and heart disease is significantly lower in southern China than in northern China, we consulted main risk factors of cardiovascular disease ${ }^{[32]}$, high sodium diet, smoking, 
insufficient physical activity, insufficient intake of omega-3 polyunsaturated fatty acids, obesity and overweighed, insufficient intake of vegetables and fruits are leading risk factors of CVD. In recent years, studies found that PM2.5 exposure, high temperature and low temperature are important risk factors to CVD. Therefore, we select the above 9 risk factors as research objects.

1) Vegetables and fruit intake:

Data of per capita vegetable (including vegetables and edible fungi) and fruit (including fresh and dried fruits) intake of 31 provinces were obtained from China Statistical Yearbook (2016, 2017, 2018, http://www.stats.gov.cn/tjsj/ndsj/), as shown in Fig.5 (A) and Fig.5 (B).

2) Tobacco:

Tobacco exposure is one of the main risk factors for cardiovascular diseases. However, investigation of tobacco exposure involves smoking rate, smoking amount, cessation rate and relapse rate, etc. Only through careful investigation of a large number of people can accurate results be obtained. The data of smoking rates in the same region collected by different institutions and different periods are quite different. Therefore, we use the data of per capita tobacco sales rather than the data of smoking rates. The data of tobacco sales are obtained from tobacco sales statistics websites in China (http://www.yanb2b.com, etc.). The calculation method is shown in Equation (2). The per capita tobacco sales data in each province is shown in Fig.5(C).

$$
T_{i}=\frac{K_{i}}{P_{i}}, P_{i}=L_{i}+M_{i}
$$

Where, $T_{i}$ is per capita tobacco sales of each province, $K_{i}$ represents the tobacco sales of each province, $P_{i}$ represents the total population of each province, $L_{i}$ represents the permanent residents of each province, and $M_{i}$ is the floating population of each province.

3) Salt (sodium) intake:

Data on regional salt intake varied from different studies. In order to accurately calculate risk of sodium, we collected salt intake data from different data soure ${ }^{[33,34]}$ and calculated the average value in each province. The result is illustrated in Fig.5(D). 4) PM2.5:

Data of PM2.5 is from national urban air quality real-time publishing platform (http://106.37.208.233:20035/) owned by China's environmental monitoring centre. We collected the daily PM2.5 data of 1619 stations located in 31 provinces from 2014.05.13 to 2019.12.31. The distribution of 1619 PM2.5 monitoring stations is shown in Fig.4 (right). We used the Inverse Distance Weighted method to get the PM2.5 concentration grid graph of China (resolution: $1 \mathrm{~km} \times 1 \mathrm{~km}$ ). The average 
PM2.5 data of monitoring stations located in each province cannot represent the accurate PM2.5 of residential areas as many porvinces in China cover both flat and steep, mountainous topography, and population density is much higher in flat areas than in mountainous areas. Therefore, we collected a $1 \mathrm{~km} \times 1 \mathrm{~km}$ population density grid map (http://www.resdc.cn), and calculated population density weighted average PM2.5 (PDP) of each province. Areas with greater populations in procinces were given greater weights in the average PM2.5 calculation, which can be expressed as follows:

$$
P D P_{i}=\frac{\sum_{i=1}^{n}\left(P O_{i} \times P M_{i}\right)}{\sum_{i=1}^{n} P O_{i}}
$$

Where $n$ is the number of grids of each province, $P O_{i}$ is the population of grid $i$ $(1 \mathrm{~km} \times 1 \mathrm{~km})$ in a province and $P M_{i}$ is the PM2.5 of grid $i(1 \mathrm{~km} \times 1 \mathrm{~km})$ in a province.

The PDP map was created based on Eq. (3), and the results are illustrated in Fig. $5(\mathrm{E})$.

5) Aquatic intake:

The data of aquatic intake is from China Statistical Yearbook (http://www.stats.gov.cn/tjsj/ndsj/). We collected the average annual aquatic product intake of each province from 2016 to 2018, and the per capita aquatic intake is shown in Fig.5 (F).

6) Obesity and overweight rate:

Data of obesity rate and overweight rate are from Chinese Center for Disease Control and Prevention ${ }^{[35]}$. We collected the obesity rate and overweight rate of people in all provinces in 2013. The result is illustrated in Fig.5 (G).

7) Low temperature and high temperature:

The temperature data is from China Meteorological Data Network (http://data.cma.cn). We collected daily temperature data from 756 temperature monitoring stations across the country in 2000 and 2010. The geographical distribution of national temperature monitoring stations is shown in Fig.4 (left). By calculating average data of the same day at each provincial temperature monitoring station, we get the daily average temperature of each province in China. Relevant studies have shown that the average daily temperature above 26 degree centigrade or below 10 degree centigrade will lead to an increase in death and cardiovascular disease incidence ${ }^{[36]}$, and the risk increases with the rise of temperature ( $>26$ degree centigrade) or the decrease of temperature $(<10$ degree centigrade). Based on the monitoring data from each station, we calculated the yearly number of days of each temperature grade $(26 \sim 27,27 \sim 28,28 \sim 29,29 \sim 30,30 \sim 31,>31,5 \sim 9,0 \sim 4,-5 \sim-1,-10 \sim-6$, $-15 \sim-11,<-15)$ in each province. As shown in Fig.5(H) and Fig.5 (I). 

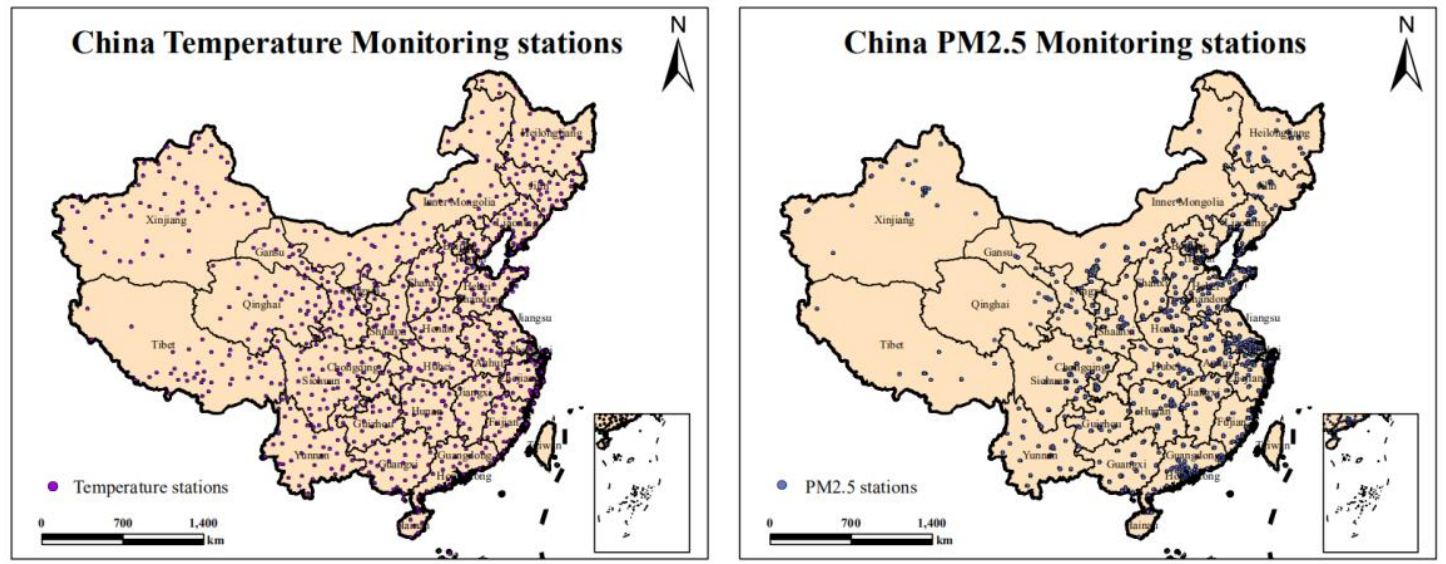

Fig.4 China's temperature monitoring stations and PM2.5 monitoring stations
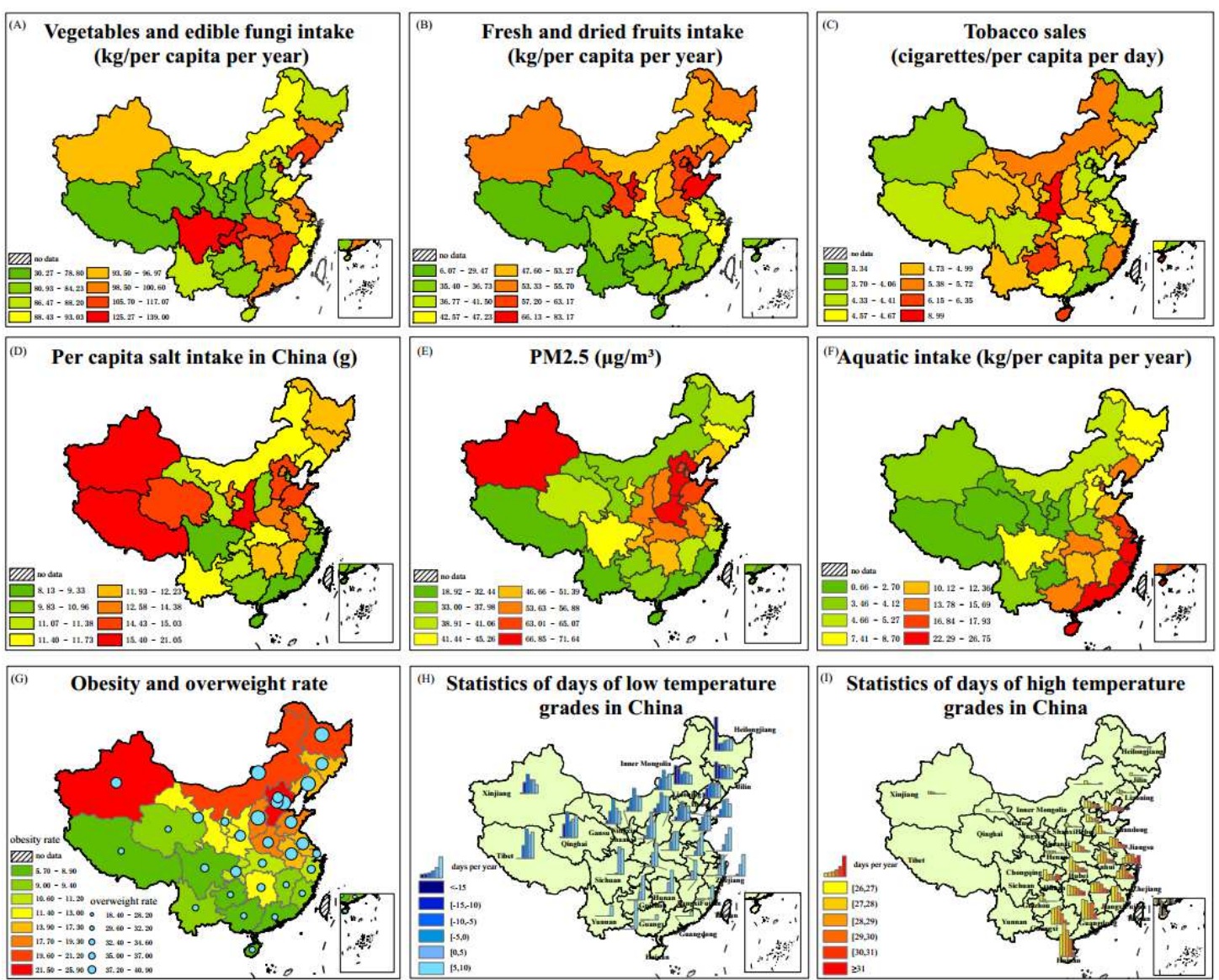

Fig.5 Nine risk factors of CVD

\subsection{Contribution of each factor on provincial CVD}

To quantitatively study the contribution of nine risk factors on provincial CVD mortality, we calculated the estimation of attributable disease burden according to theory and methodology in Global Burden of Disease (GBD) ${ }^{[37]}$. In GBD, the estimation of disease burden attributed by various risk factors is carried out under the framework of comparative risk assessment theory. The core content of the theory is: when the exposure level of other independent risk factors remains unchanged, the proportion of disease burden attributed to a certain risk factor (population attribution 
fraction, PAF) is calculated by comparing the exposure distribution of the risk factor with the theoretical minimum risk exposure distribution, the formula of PAF is as shown in formula (4), then the attributed number of death and mortality rate is calculated in formula (5):

$$
\begin{array}{r}
P A F=\frac{\sum_{i=1}^{n} P_{i}\left(R R_{i}-1\right)}{\sum_{i=1}^{n} P_{i}\left(R R_{i}-1\right)+1} \\
A M=P A F \times M
\end{array}
$$

Where, $R R_{i}$ is relative risk at exposure level $i, P_{i}$ is proportion of population at exposure level $i$. the relative risk (RR) and its $95 \% \mathrm{CI}$ of each risk factor is from Global Burden of Disease 2017 (http://ghdx.healthdata.org/gbd-2017). $A M$ is attributed number of death of a risk factor, $M$ is number of death of CVD.

The calculation of nine risk factors can be divided into two categories:

(1) The attributable risk proportion of PM2.5, obesity, smoking, diet low in vegetable intake, diet low in fruit intake, diet high in sodium, diet low in omega-3 fatty acids are calculated by formula (4) and formula (5). The per capita omega-3 fatty acids intake of each province was calculated based on the data of provincial aquatic intake and average omega-3 fatty content of a variety of aquatic products in China.

(2) Contribution of high temperature and low temperature

Temperature is an important risk factor for CVD, a large number of studies have shown that both high and low temperature environment will increase the incidence of CVD and mortality, and temperature has a lagging effect of CVD, high temperature effects appear to last for a few days, whereas the effects of low temperature may persist for up to several weeks ${ }^{[38]}$. We calculated the RR of annual high temperature and annual low temperature in each province based on the RR of lag days of each incidence of high temperature and low temperature (), the formula is as follows:

$$
R R_{k}^{\text {one year }}=1+\sum\left(\frac{\sum_{i=1}^{n} R R_{k}^{i}-n}{365} \times d_{k}\right)
$$

Where, $k$ is average temperature in a day, at low temperature, $k \in\left(-25^{\circ} \mathrm{C}, 9^{\circ} \mathrm{C}\right)$, at high temperature, $k \in\left(26^{\circ} \mathrm{C}, 33^{\circ} \mathrm{C}\right), n$ is the lag days that $\mathrm{RR}$ and its $95 \% \mathrm{CI}$ both $>1, R R_{i}$ is relative risk of temperature $k$ at day $i$ of lag, $i \in(0,30), d_{k}$ is the number of days in a year that average temperature $=k$.

The standardized CVD mortality rate of nine risk factors of each province are illustrated in Fig.6. The average value of attributable risk proportion of 15 northern provinces and 15 southern provinces is illustrated in Table 4 and Table 5. 

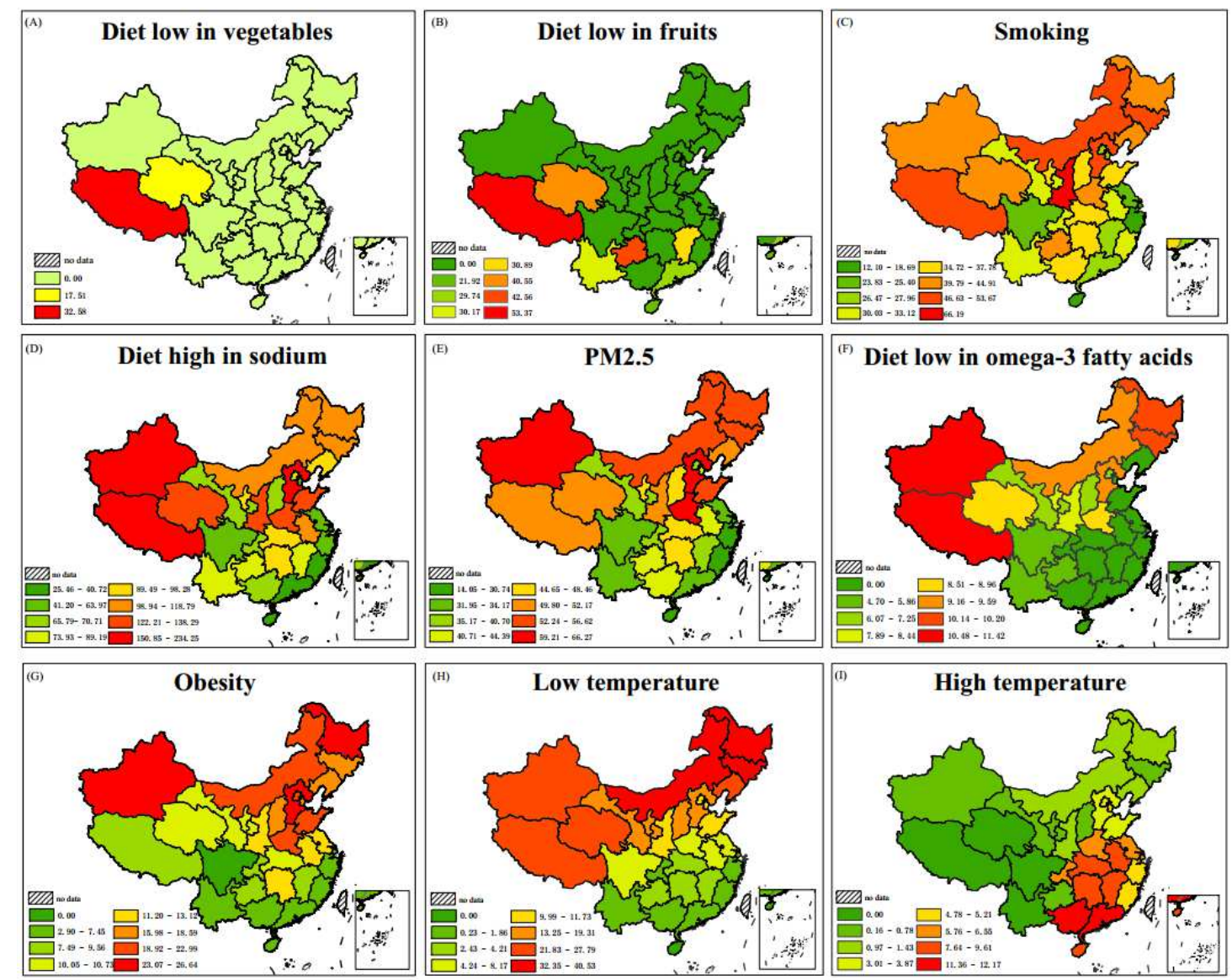

Fig.6 attributable risk proportion of nine risk factors of CVD in each province

Table 4 Contribution of risk factors of heart disease in northern and southern China

\begin{tabular}{|c|c|c|c|c|c|c|c|c|c|}
\hline & sodium & vegetable & fruit & smoking & PM2.5 & Omega-3 & Obesity & LT & HT \\
\hline Northern & $38.1 \%$ & $0.7 \%$ & $0.5 \%$ & $14.7 \%$ & $18.1 \%$ & $4.0 \%$ & $4.7 \%$ & $5.6 \%$ & $0.6 \%$ \\
\cline { 2 - 10 } China and & $21.0 \% \sim$ & $0.3 \% \sim$ & $0.2 \% \sim$ & $11.6 \% \sim$ & $16.1 \% \sim$ & $1.6 \% \sim$ & $4.0 \% \sim$ & $3.0 \% \sim$ & $0.5 \% \sim$ \\
$95 \%$ CI & $70.5 \%$ & $1.0 \%$ & $0.7 \%$ & $20.8 \%$ & $20.1 \%$ & $6.5 \%$ & $7.4 \%$ & $8.1 \%$ & $0.8 \%$ \\
\hline Southern & $29.0 \%$ & $0 \%$ & $2.5 \%$ & $14.6 \%$ & $16.7 \%$ & $1.0 \%$ & $2.7 \%$ & $0.9 \%$ & $2.7 \%$ \\
\cline { 2 - 10 } China and & $15.0 \% \sim$ & $0.0 \% \sim$ & $0.9 \% \sim$ & $11.5 \% \sim$ & $14.6 \% \sim$ & $0.4 \% \sim$ & $2.3 \% \sim$ & $0.5 \% \sim$ & $2.0 \% \sim$ \\
$95 \%$ CI & $65.8 \%$ & $0.0 \%$ & $3.7 \%$ & $20.6 \%$ & $18.7 \%$ & $1.6 \%$ & $4.4 \%$ & $1.3 \%$ & $3.3 \%$ \\
\hline Differential & $9.1 \%$ & $0.7 \%$ & $-2.0 \%$ & $0.1 \%$ & $1.4 \%$ & $3.0 \%$ & $2.0 \%$ & $4.7 \%$ & $-2.1 \%$ \\
\hline
\end{tabular}

LT: Low temperature; HT: High Temperature

Table 5 Contribution of risk factors of cerebrovascular disease in north and southern

259

China

\begin{tabular}{|c|c|c|c|c|c|c|c|c|c|}
\hline & sodium & vegetable & fruit & smoking & PM2.5 & Omega-3 & Obesity & LT & HT \\
\hline Northern & $34.9 \%$ & $0.0 \%$ & $1.0 \%$ & $9.5 \%$ & $12.3 \%$ & $0.0 \%$ & $5.9 \%$ & $5.6 \%$ & $0.6 \%$ \\
\cline { 2 - 10 } China and & $24.0 \% \sim$ & $0.0 \% \sim$ & $0.5 \% \sim$ & $8.9 \% \sim$ & $9.6 \% \sim$ & $0.0 \% \sim$ & $4.2 \% \sim$ & $3.1 \% \sim$ & $0.5 \% \sim$ \\
$95 \%$ CI & $44.4 \%$ & $0.0 \%$ & $1.5 \%$ & $22.8 \%$ & $14.3 \%$ & $0.0 \%$ & $9.5 \%$ & $8.0 \%$ & $0.8 \%$ \\
\hline Southern & $26.2 \%$ & $0.0 \%$ & $5.2 \%$ & $9.4 \%$ & $11.3 \%$ & $0.0 \%$ & $3.5 \%$ & $0.9 \%$ & $2.7 \%$ \\
\cline { 2 - 10 } China and & $17.4 \% \sim$ & $0.0 \% \sim$ & $2.9 \% \sim$ & $8.7 \% \sim$ & $8.9 \% \sim$ & $0.0 \% \sim$ & $2.5 \% \sim$ & $0.5 \% \sim$ & $2.0 \% \sim$ \\
$95 \%$ CI & $34.6 \%$ & $0.0 \%$ & $7.6 \%$ & $22.6 \%$ & $13.3 \%$ & $1.0 \%$ & $5.7 \%$ & $1.3 \%$ & $3.3 \%$ \\
\hline Differential & $8.7 \%$ & $0.0 \%$ & $-4.2 \%$ & $0.1 \%$ & $1.0 \%$ & $0.0 \%$ & $2.4 \%$ & $4.7 \%$ & $-2.1 \%$ \\
\hline
\end{tabular}




\section{Discussion}

Longevity level in northern provinces was significantly lower than that in southern provinces of China (Table 1), this is significantly correlated with CVD. Fig.2, Fig.3, Table 2 and Table 3 illustrate that among the four major diseases, major tumors is randomly distributed in China. Additionally, the mortality rate of respiratory diseases is generally higher in southern China than in northern China. Conversely, the mortality rate of CVD is generally lower in southern China than in northern China, which is consistent with other studies, a study found nine provinces in northern China, namely Heilongjiang, Jilin, Liaoning, Inner Mongolia, Hebei, Beijing, Ningxia, Tibet, and Xinjiang, have a high incidence of stroke, constituting a stroke belt. The stroke incidence in the stroke zone was $236.2 / 100,000$, which was significantly higher than that in the areas outside the stroke zone $(109.7 / 100,000)^{[39]}$. Because mortality rate of CVD is considerably higher than that of respiratory diseases, a lower mortality rate of CVD in southern China led to higher life expectancy and longevity ratio. Similar things happen in other countries that stagnating decline in cardiovascular disease (CVD) mortality was the main culprit for life expectancy stalls of America since 2010 [40].

Among the nine risk factors shown in Fig.5, exposure risk of six factors are higher in northern China than in southern China. Residents living in northern China have lower vegetable intake, higher sodium intake, higher PM2.5 exposure, higher insufficient intake of aquatic products, higher obesity rate and overweight rate, and lower temperature. However, only two risk factors in southern China have higher exposure risk than those in northern China, they are fruit intake and high temperature. In addition, there is no obvious difference between the north and the south in the exposure risk of tobacco.

Salt intake is significantly higher in northern China than in southern China, one reason is that residents in northern China is exposed to lower temperature and they are used to eat more salt to fight the cold. In addition, determined by the geographical and climatic conditions, in northern winter, residents could not eat fresh vegetables in the past, they had to marinate the vegetables with heavy salt to prevent decay. After a long time, the taste naturally became heavier. Diet high in sodium has the greatest impact on blood pressure. $40 \%$ of hypertension incidents is caused by high salt diet, and hypertension is the primary risk factor of CVD and all-cause mortality in the global burden of disease ${ }^{[41]}$. Fig.6, Table 4, Table 5 tell us sodium exposure is leading risk factor of CVD in China, which is in accordance with former studies ${ }^{[24,25]}$, and sodium exposure is also the leading reason of north-south differential of CVD mortality rate. 
Regions with generally higher PM2.5 concentrations are located in northern China, especially in the areas around Beijing, the capital of China, it is the area with the most intensive heavy industry and consumed the most quantity of coal. The climatic characteristics of the Beijing-Tianjin-Hebei region are also one of the reasons for the increase in pollution, weak wind, quiet and stable weather and a lower atmospheric boundary layer are conducive to the accumulation and formation of aerosols. In addition, China's Huai River policy provides free or heavily subsidized coal for indoor heating during the winter to cities north of the Huai River but not to those to the south, which lead to large amount of particulate matter emission in northern China, and reduces life expectancy by 3.1 years, the shorter lifespans are almost entirely caused by elevated rates of cardiorespiratory mortality ${ }^{[42]}$. In this study, PM2.5 is a main dangerous reason of north-south differential of CVD mortality rate.

The obesity rate and overweight rate are significantly higher in northern China than in southern China. The top 10 provinces with highest obesity rates are all located in the north. This is due to the different eating habits in the north and south. In addition, the cold and long winter in northern China is not good for going out and have physical activities, residents in northern China prefer to stay indoors and eat more food to resist the cold temperature.

The aquatic intake is higher in southern China than in the north. This is mainly due to the difference geographic condition between the north and south. For sea food, among the 11 coastal provinces in China, 7 of them located in the south and 4 in the north. Southern China have longer coastline, vaster and deeper sea area, more fishing grounds, and more abundant fishery resources. For freshwater food, benefited from the monsoon climate, southern China has abundant rainfall and developed river system, these advantages bring abundant fishery categories and resources. Northern China is mainly covered by dry inland climate, which is not conducive to fishing and aquaculture. Therefore, the daily consumption of aquatic is much higher in southern China than in northern China. This study shows that there are 16 provinces have lower than $100 \mathrm{mg}$ daily omega-3 fatty acids intake (the standard line in GBD 2017), except Tibet, 12 of them located in northern China and 3 in southern China.

Although both intensely hot temperature and cold temperature will cause an increase in the mortality rate ${ }^{[43]}$, the relationship between hot temperature and death and cold temperature and death are different. Some studies have reported more cold-related than heat-related deaths [44,45]. And although the immediate high temperature will cause higher risk than cold temperature, the accumulated risk of high temperate is lower than low temperature, because the effect of cold temperatures 
persisted for several days ${ }^{[46,47]}$, whereas the effect of high temperatures was restricted to the day of the death or the immediately preceding day ${ }^{[48]}$. That is why number of death caused by extreme temperature in northern China is larger than southern China.

\section{Conclusion}

This paper explained why people in southern China live longer than those in northern China. The contributions of heart disease, cerebrovascular disease, main tumor and respiratory disease to longevity in northern China and southern China were calculated. The results showed that heart disease and cerebrovascular disease were the main reasons for the residents in southern China to live longer than those in northern China.

To study why death rate of CVD is much higher in northern China than in southern China, nine important risk factors for CVD were selected: high sodium diet, smoking, insufficient intake of omega-3 polyunsaturated fatty acids, obesity and overweight, insufficient intake of vegetables and fruits, PM2.5, high temperature and low temperatures. Based on relative risk of each factor of GBD 2017, the population attribution fraction of nine factors in each province was calculated, and the age-standardized CVD mortality rate attributed to each factor was obtained.

The results show that, among the nine risk factors, northern China have higher exposure value and attributable risk proportion of six risk factors, residents live in northern China eat more sodium, less vegetable and less sea products, they are more likely to be overweight. PM2.5 is much higher in northern China than in southern China. Cold temperature causes more number of death than hot temperature because of the longer cumulative risk, all these factors lead to higher CVD mortality rate, shorter life expectancy and lower life span in northern China.

Ethics approval and consent to participate

Not applicable

Consent for publication

Not applicable

Availability of data and material

All data generated or analyzed during this study are included in this published article.

Competing interests

The authors declare that they have no competing interests.

Funding

Not applicable

Authors' contributions 

final manuscript.

\section{References}

1 Li Wang, Binggan Wei, Yonghua Li, et al. A study of air pollutants influencing life expectancy and longevity from spatial perspective in China. Science of the Total Environment 2014;487:57-64.

2 Wenjin Song, Yonghua $\mathrm{Li}$, Zhe Hao, et al. Public health in China: an environmental and socio-economic perspective. Atmospheric Environment 2016;129:9-17.

3 Yuan Liu, Yonghua Li, Yu Jiang, et al. Effects of Soil Trace Elements on Longevity Population in China. Biological Trace Element Research 2013;153:119-26.

4 Weixia Sun, Biao Huang, Yongcun Zhao, et al. Spatial variability of soil selenium as affected by geologic and pedogenic processes and its effect on ecosystem and human health. Geochemical Journal 2009;43:217-25.

5 Christensen, K., \& Vaupel, J. W. (1996). Determinants of longevity: Genetic, environmental and medical factors. Journal of Internal Medicine, 240, 333-341.

6 WHO (World Health Organization) (2011). Global health and aging. Available online: http://www.who.int/ageing/publications/global_health.pdf.

$7 \mathrm{Yu}$ W, Mengersen K, Wang X, et al. Daily average temperature and mortality among the elderly: a meta-analysis and systematic review of epidemiological evidence. Int $\mathrm{J}$ Biometeorol. 2012;56:569-81.

8 Hajat S, Kosatky T. Heat-related mortality: a review and exploration of heterogeneity. J Epidemiol Community Health 2010;64:753-60.

9 Basu R, Samet JM. Relation between elevated ambient temperature and mortality: a review of the epidemiologic evidence. Epidemiol Rev. 2002;24:190-202

10 Basu R. High ambient temperature and mortality: a review of epidemiologic studies from 2001 to 2008. Environ Health. 2009;8:40.

11 Dimitriou K, McGregor G, Kassomenos P, Paschalidou A. Exploring winter mortality variability in five regions of England, using back trajectory analysis. Earth Interact. 2016;20 (1):1-27.

12 Paschalidou AK, Kassomenos PA, McGregor GR. Analysis of the synoptic winter mortality climatology in five regions of England: Searching for evidence of weather signals. Sci Total Environ. 2017;598:432-44.

13 Kan H, London SJ, Chen H, et al. Diurnal temperature range and daily mortality in Shanghai, China. Environ Res. 2007;103:424-31.

14 Kysely J, Pokorna L, Kyncl J, Kriz B. Excess cardiovascular mortality associated with cold spells in the Czech Republic. BMC Public Health 2009;9:19; doi:10.1186/1471-2458-9-19.

15 Yang G,Wang Y, Zeng Y, et al. Rapid health transition in China, 1990-2010: fi ndings from the Global Burden of Disease Study 2010. Lancet, 2013, 381(9882): 1987-2015.

16 Xie W, Li G, Zhao D, et al. Relationship between fine particulate air pollution and ischaemic heart disease morbidity and mortality. Heart, 2015,101:257-263.

17 Brook RD, Rajagopalan S, Pope CA, Brook JR, Bhatnagar A, Diez-Roux AV, Holguin F, Hong YL, Luepker RV, Mittleman MA, Peters A, Siscovick D, Smith SC, Whitsel L, Kaufman JD. Particulate matter air pollution and cardiovascular disease: an update to the scientifc statement from the American Heart Association. Circulation. 2010;121:2331-78.

18 Pope CA, Brook RD, Burnett RT, Dockery DW. How is cardiovascular disease mortality risk afected by duration and intensity of fine particulate matter exposure? An integration of the epidemiologic evidence. Air Qual Atmos Hlth. 2011;4(1):5-14.

19 Dominici F, Peng RD, Bell ML, Pham L, McDermott A, Zeger SL, Samet JM. Fine particulate air pollution and hospital admission for cardiovascular and respiratory diseases. Jama J Am Med Assoc. 2006;295(10):1127-34. 
20 Ge EJ, Lai KF, Xiao X, Luo M, Fang ZF, Zeng YJ, Ju H, Zhong NS. Diferential efects of size-specifc particulate matter on emergency department visits for respiratory and cardiovascular diseases in Guangzhou, China. Environ Pollut. 2018;243(12):336-45.

21 Ma Y, Zhang H, Zhao Y, et al. Short-term effects of air pollution on daily hospital admissions for cardiovascular diseases in western China. Environ Sci Pollut Res Int, 2017,24(16):14071-14079.

22 Bennett DA, Du H, Clarke R, et al. Association of Physical Activity With Risk of Major Cardiovascular Diseases in Chinese Men and Women. JAMA Cardiol, 2017,2(12):1349-1358

23 Liu Y, Wen W, Gao YT, et al. Level of moderate-intensity leisure-time physical activity and reduced mortality in middle-aged and elderly Chinese. J Epidemiol Community Health, 2018,72(1):13-20.

24 GBD 2017 diet collaborators. Health effects of dietary risks in 195 countries, 1990-2017: a systematic analysis for the Global Burden of Disease Study 2017. The Lancet 2019,393, 1958-1972.

25 Mozaffarian D, Fahimi S, Singh GM, et al. Global sodium consumption and death from cardiovascular causes. N Engl J Med, 2014, 371(7): 624-634. DOI: 10.1056/NEJMoa1304127.

26 Chen Z, Iona A, Parish S, et al. Adiposity and risk of ischaemic and haemorrhagic stroke in 0.5 million Chinese men and women: a prospective cohort study. Lancet Glob Health, 2018,6(6):e630-e640.

27 Li Y, Wang DD, Ley SH, et al. Potential Impact of Time Trend of Life-Style Factors on Cardiovascular Disease Burden in China. J Am Coll Cardiol, 2016,68(8):818-833.

28 Yang Y, Dong B, Zou Z, et al. Association between Vegetable Consumption and Blood Pressure, Stratifi ed by BMI, among Chinese Adolescents Aged 13-17 Years: A National Cross-Sectional Study. Nutrients, 2018,10, 451; dol: 10.3390

29 National health commission of People's Republic of China. China Health Statistics Yearbook. Peking union medical college press.

30 Chinese Center for Disease Control and Prevention. China Death Cause Surveillance Data Set 2013.

31 Report on Chinese Residents' Chronic Disease and Nutrition 2015, People's Medicine Publishing House.

32 Yanping Li, Dong D Wang, Sylvia H. Ley, et al. Potential Impact of Time Trend of Life-Style Factors on Cardiovascular Disease Burden in China. Journal of the American college of cardiology, 2016,68(8):818-833.

33 Hipgrave D B , Chang S, Li X , et al. Salt and Sodium Intake in China. Jama, 2016, 315(7):703-705.

34 Liu Min, Li Yichong, Liu Shiwei, et al. Burden of disease attributable to high- sodium diets in China, 2013. Chin J Prev Med, 2016,50(09):759-763.

35 Chinese center for disease control and prevention. Report on Chronic disease risk factor surveillance in China 2013. Military Medical Press, 2016.

36 Armstrong B. Models for the relationship between ambient temperature and daily mortality. Epidemiology. 2006;17(6):624-31.

37 Lim SS, Vos T, Flaxman AD, et al. A comparative risk assessment of burden of disease and injury attributable to 67 risk factors and risk factor clusters in 21 regions, 1990-2010: a systematic analysis for the Global Burden of Disease Study 2010. Lancet, 2012, 380(9859): 2224-2260. DOI: 10.1016/S0140-6736(12)61766-8

38 Braga AL, Zanobetti A, Schwartz J. The time course of weather-related deaths. Epidemiology 2001;12(6):662-7

39. Xu Gelin, Ma Minmin, Liu Xinfeng. Is there a stroke belt in China and why? Stroke 2013;44:1775-83.

40 Neil K. Mehta, Leah R. Abrams, Mikko Myrskylä. US life expectancy stalls due to cardiovascular disease, not drug deaths. PNAS, 2020,117(13):6998-7000; https://doi.org/10.1073/pnas.1920391117.

41 Lim SS, Vos T, Flaxman AD, et al. A comparative risk assessment of burden of disease and injury attributable to 67 risk factors and risk factor clusters in 21 regions, 1990-2010: a systematic analysis for the Global Burden of Disease Study 2010. Lancet, 2012, 
380(9859):2224-2260.

42 Avraham Ebenstein, Maoyong Fan, Michael Greenstone, Guojun He, and Maigeng Zhou. New evidence on the impact of sustained exposure to air pollution on life expectancy from China's Huai River Policy. PNAS,2017, 616784114.

43 Heaviside C, Tsangari $\mathrm{H}$, Paschalidou A, et al. Heat-related mortality in Cyprus for current and future climate scenarios. Sci Total Environ. 2016;569-570:627-33.

44 Ballester F, Michelozzi P, Iñiguez C. Weather, climate and public health. J Epidemiol Community Health. 2003;57:759-60.

45 Kalkstein LS, Greene JS. An evaluation of climate/mortality relationship in large U.S. cities and the possible impacts of a climate change. Environ Health Perspect. 1997;105:84-93.

46 Bell ML, O’Neill MS, Ranjit N, Borja-Aburto VH, Cifuentes LA, Gouveia NC (2008). Vulnerability to heat-related mortality in Latin America: a case-crossover study in São Paulo, Brazil, Santiago, Chile and Mexico City, Mexico. Int J Epidemiol 37:796-804.

47 Hertel S, Le Tertre A, Jöckel KH, Hoffmann B. 2009. Quantification of the heat wave effect on cause-specific mortality in Essen, Germany. Eur J Epidemiol 24:407-414.

48 Alfésio LF, Antonella Z, Joel S (2002). The Effect of Weather on Respiratory and Cardiovascular Deaths in 12 U.S. Cities, Environmental Health Perspectives, 110(9): 859-863. 


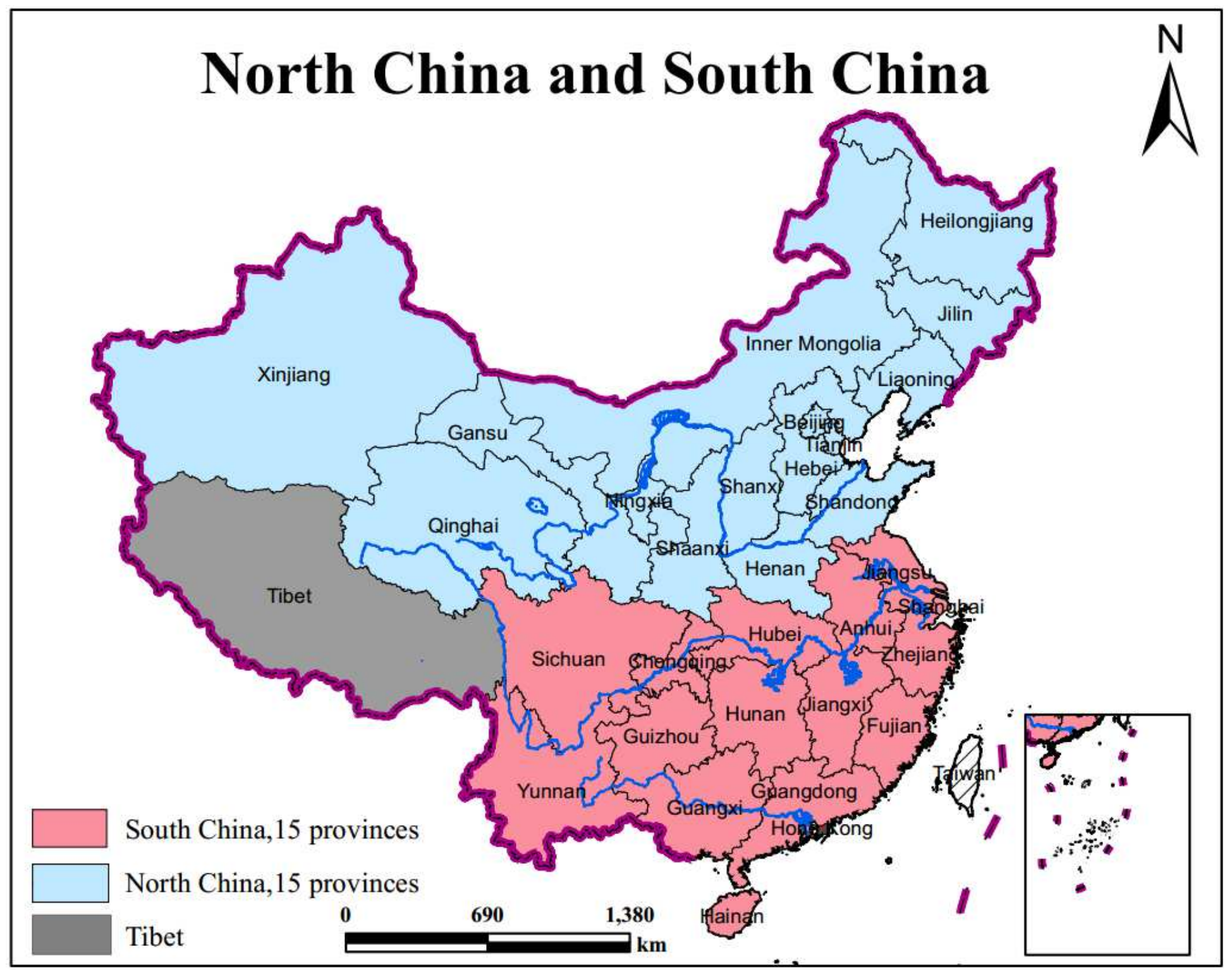

Figure 1

Northern China and Southern China Note: The designations employed and the presentation of the material on this map do not imply the expression of any opinion whatsoever on the part of Research Square concerning the legal status of any country, territory, city or area or of its authorities, or concerning the delimitation of its frontiers or boundaries. This map has been provided by the authors. 

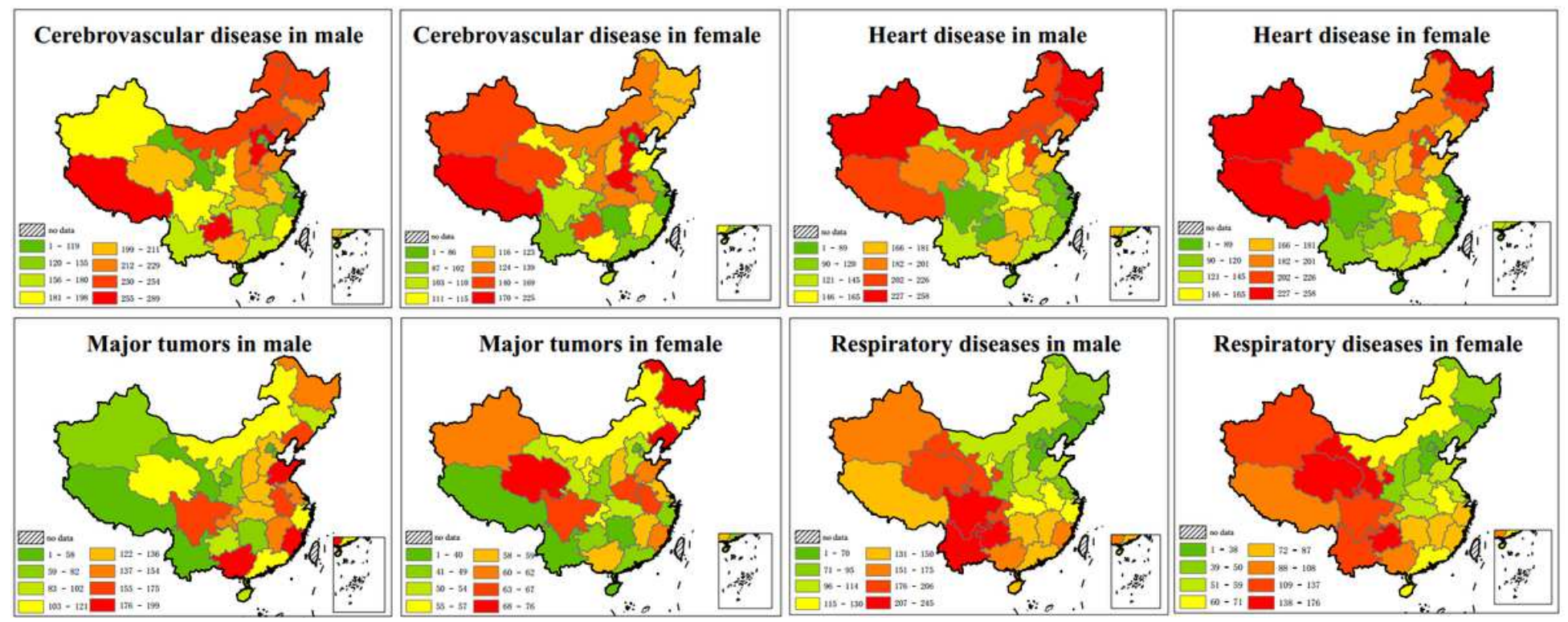

\section{Figure 2}

Distribution of age-standardized mortality rates of four major fatal diseases. Warmer colors indicate higher mortality rate Note: The designations employed and the presentation of the material on this map do not imply the expression of any opinion whatsoever on the part of Research Square concerning the legal status of any country, territory, city or area or of its authorities, or concerning the delimitation of its frontiers or boundaries. This map has been provided by the authors. 


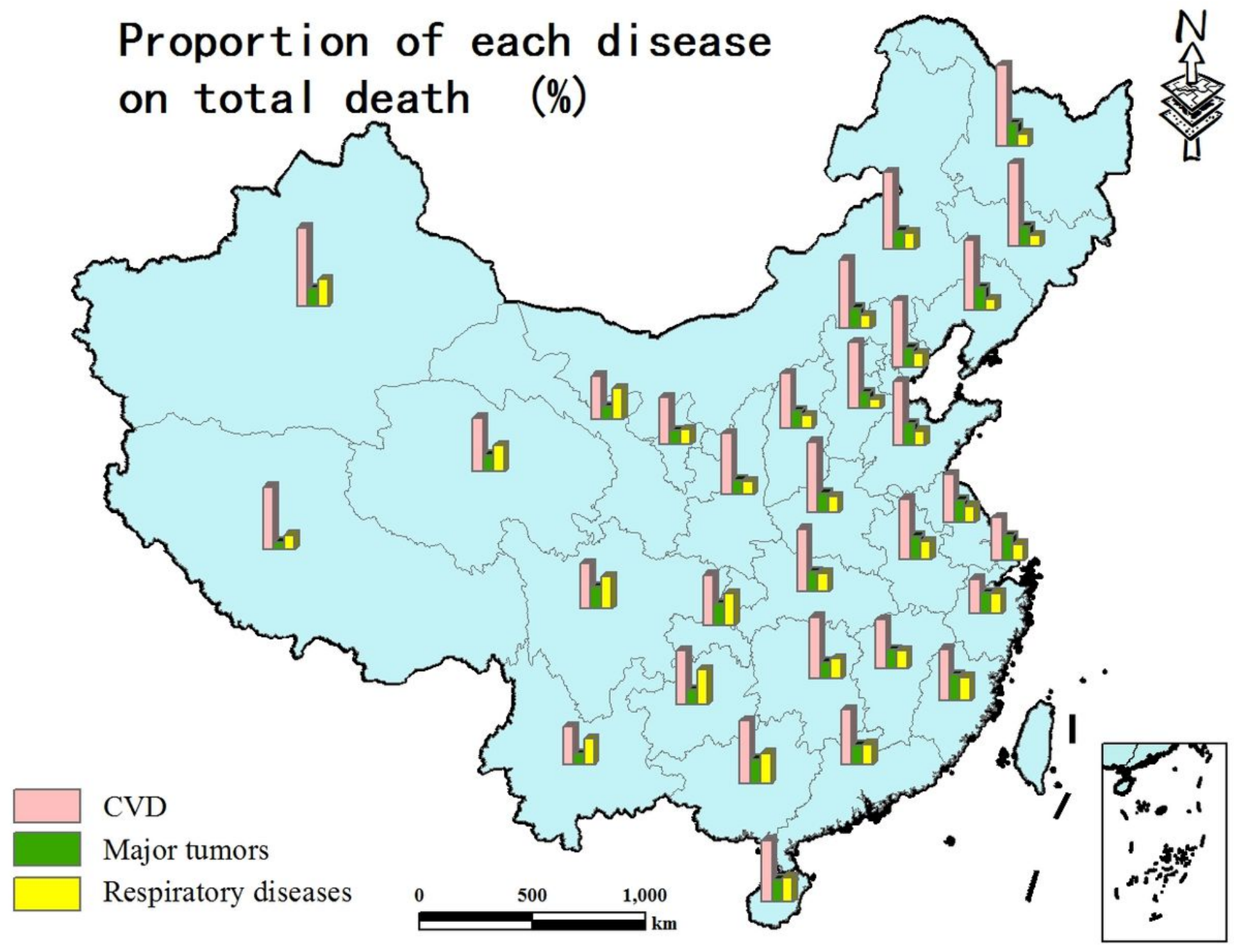

Figure 3

Proportion of each disease on total age-standardized mortality rate Note: The designations employed and the presentation of the material on this map do not imply the expression of any opinion whatsoever on the part of Research Square concerning the legal status of any country, territory, city or area or of its authorities, or concerning the delimitation of its frontiers or boundaries. This map has been provided by the authors. 

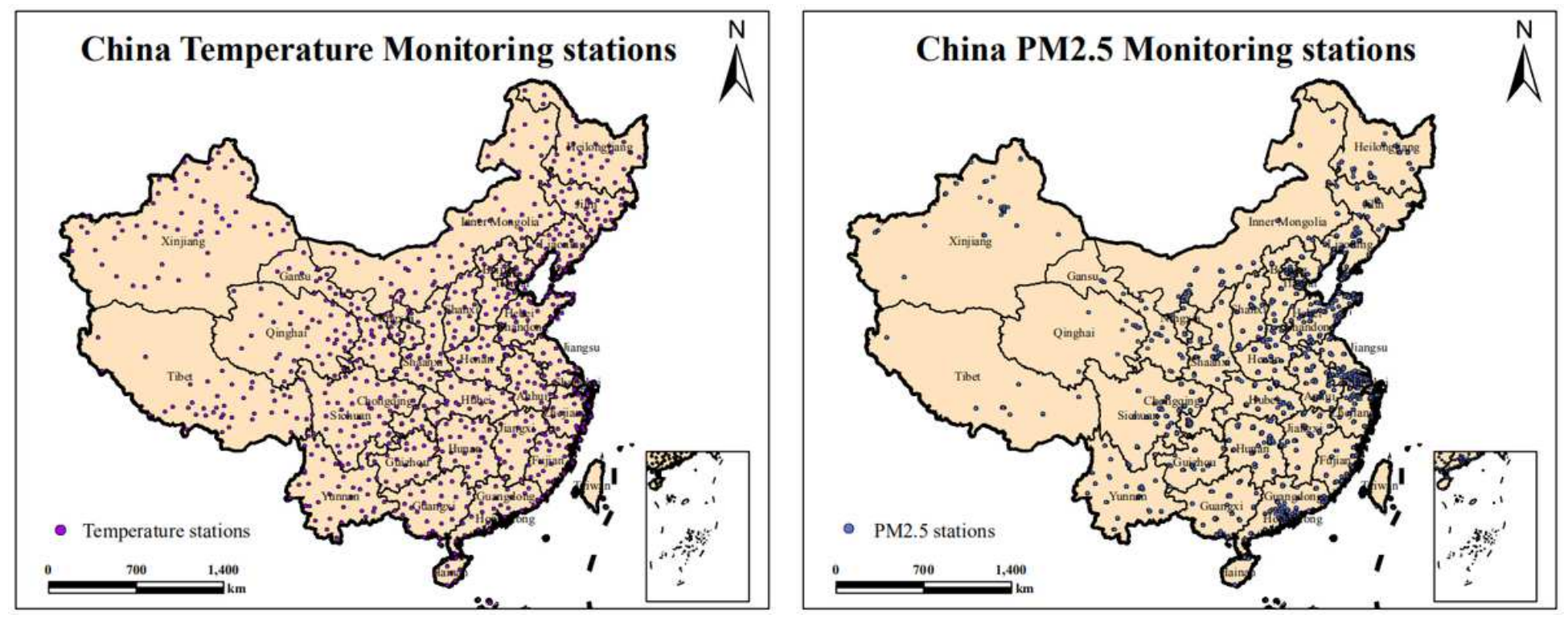

Figure 4

China's temperature monitoring stations and PM2.5 monitoring stations Note: The designations employed and the presentation of the material on this map do not imply the expression of any opinion whatsoever on the part of Research Square concerning the legal status of any country, territory, city or area or of its authorities, or concerning the delimitation of its frontiers or boundaries. This map has been provided by the authors. 

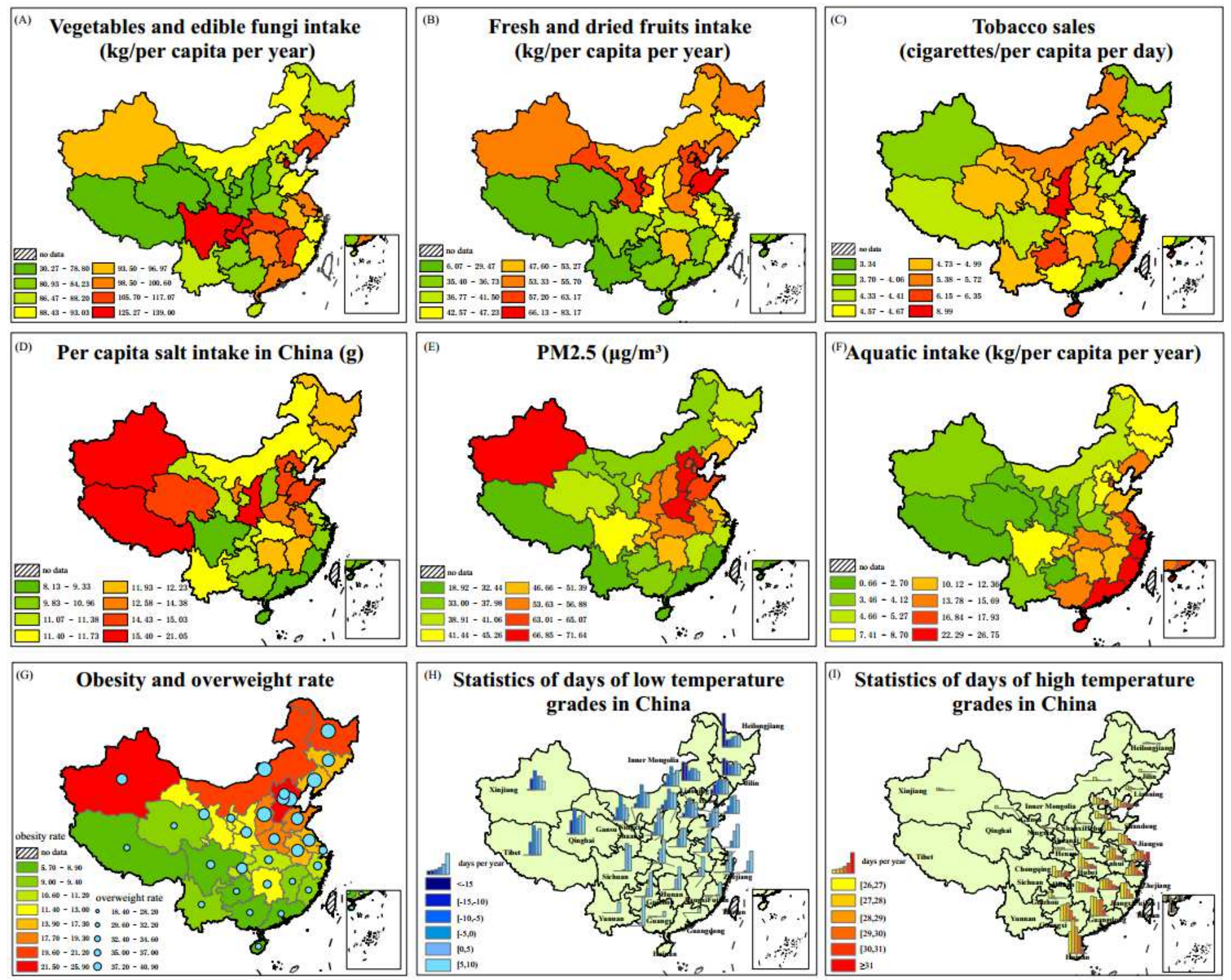

\section{Figure 5}

Nine risk factors of CVD Note: The designations employed and the presentation of the material on this map do not imply the expression of any opinion whatsoever on the part of Research Square concerning the legal status of any country, territory, city or area or of its authorities, or concerning the delimitation of its frontiers or boundaries. This map has been provided by the authors. 

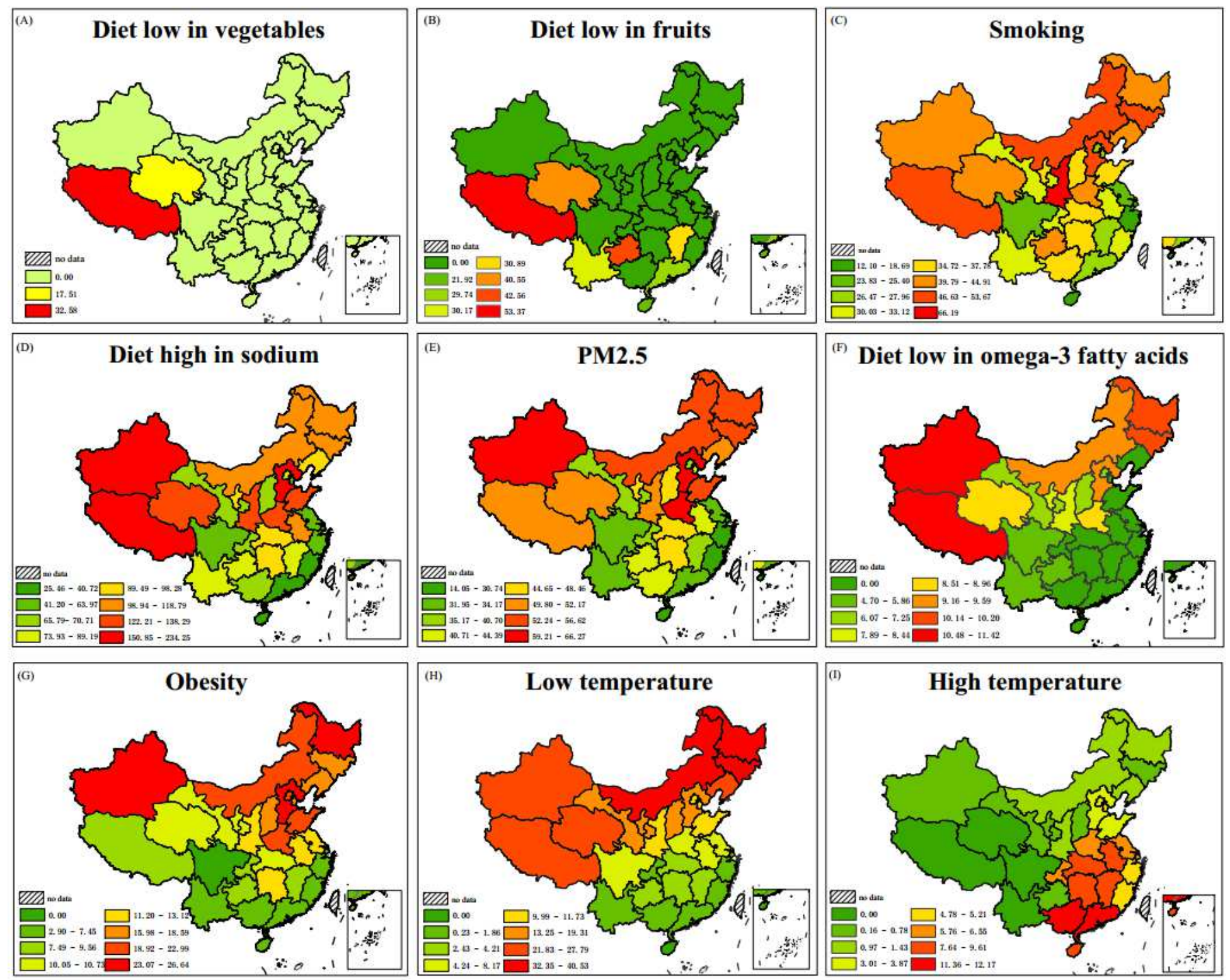

Figure 6

attributable risk proportion of nine risk factors of CVD in each province Note: The designations employed and the presentation of the material on this map do not imply the expression of any opinion whatsoever on the part of Research Square concerning the legal status of any country, territory, city or area or of its authorities, or concerning the delimitation of its frontiers or boundaries. This map has been provided by the authors. 